\title{
Deformation mechanisms that explain the combination of high plasticity and strength in steels wires with extreme carbon content
}

\author{
Elena Brandaleze ${ }^{1 *}$, Mykhaylo Romanyuk ${ }^{1}$ and Martina Avalos ${ }^{2}$ \\ ${ }^{1}$ Metallurgy Department - DEYTEMA Centre, Universidad Tecnológica Nacional, Facultad Regional San Nicolás, \\ colón 332, San Nicolás, 2900, Argentina \\ ${ }^{2}$ IFIR-Conicet, Universidad Nacional de Rosario, Ocampo y Esmeralda, Ocampo 210 bis, 2000, Rosario, Argentina \\ *Corresponding author
}

DOI: $10.5185 / \mathrm{amp} .2018 / 877$

www.vbripress.com/amp

\begin{abstract}
The alloy design concepts of high performance steels, involve the knowledge on the stability of carbides associated with nanoscale phenomena present in the structure as result of the deformation suffered during the thermomechanical processes. The understanding of the nanoscale phenomena open new frontiers to understand mechanical behaviours in the steel, not totally clarified until now. The paper discuss the structure evolution during wire drawing of pearlitic steels and the impact of cementite stability on different nanoscale structure phenomena, which explain the specific mechanical behaviour to achieve ultra-high strength. Results on the kinetic and stability of carbides predicted on the base of thermodynamic simulation are correlated with thermal analysis tests results (dilatometry and differential scanning calorimetry) carried out by different authors in order to understand the cementite $\left(\mathrm{Fe}_{3} \mathrm{C}\right)$ dissolution during plastic deformation. In addition, information obtained by traditional and no traditional microscopy techniques and $\mathrm{X}$ ray diffraction complete the study and allows to understand more deeply the structure evolution, including nanoscale phenomena that justify the mechanical behaviour during wiredrawing and the final strength level. The dislocation substructure evolution together with the cementite dissolution during sever plastic deformation which leads to a steadily increase of the strain hardening is clarified. Copyright (C) 2018 VBRI Press.
\end{abstract}

Keywords: Pearlitic steels, cold drawn, cementite stability, nanostructure, high strength.

\section{Introduction}

One of the current challenges of metallurgy is the development of ultra-high strength steels for different applications in areas, which need a combination of strength, toughness and ductility [1-3]. High plastic deformation of metals and alloys present an attracting interest as a method to obtain materials with ultrafine grain size that developed this type of mechanical behaviour. In multiphase alloys and intermetallic compounds, the severe plastic deformation processes (SPD) produce: the grain refinement, non-equilibrium solid solutions formation, disordering transformations or amorphization [4]. Texture and microstructure evolution including the curling effect caused during cold drawing, under diverse loading conditions, were also discussed on different alloys such as in tungsten and $\mathrm{Cu}-\mathrm{Fe}$ wires by Rodríguez Ripoll et al. [5] and Bolmaro et al. in [6], respectively.

The strength of high-carbon steel wires has been enhanced remarkably over the last years and it is one of the most advanced steel materials in terms of search ultra-high strength (5-6 GPa) [7]. They are considered the strongest bulk nanostructured materials. The strengthening mechanisms of cold-drawn hypereutectoid pearlitic wires can only be improved on the basis of atomic-scale investigation [8]. However, the correlation between the microstructure with many aspects related to the mechanical properties of high-carbon steel wires remain unclear until now. Such aspects include: the microstructural change resulting from wiredrawing process, significant work hardening properties characteristic of pearlitic steels and the mechanism of the delamination occurrence that is one of most important degradation problems of this type of products [1-9].

The structure of pearlite is composed of colonies within which the lamellae are essentially parallel, but differ in the orientation from the lamellae between the adjacent colonies. Fully pearlitic microstructures are highly deformable under wire drawing conditions [10]. As strain increases, in longitudinal sections, the lamellar structure of pearlite aligns itself parallel to the longitudinal wire axis and in transverse sections, the pearlitic structure becomes wavy (curling effect) and the 
lamellae within colonies are considerable curved mainly in the centre of the wire. In Fig. 1, it is possible to observe the curling aspect in the center zone of a wire $(\mathrm{C}>0.84 \%)$ cold drawn up to $3.25 \mathrm{~mm}$ of diameter.

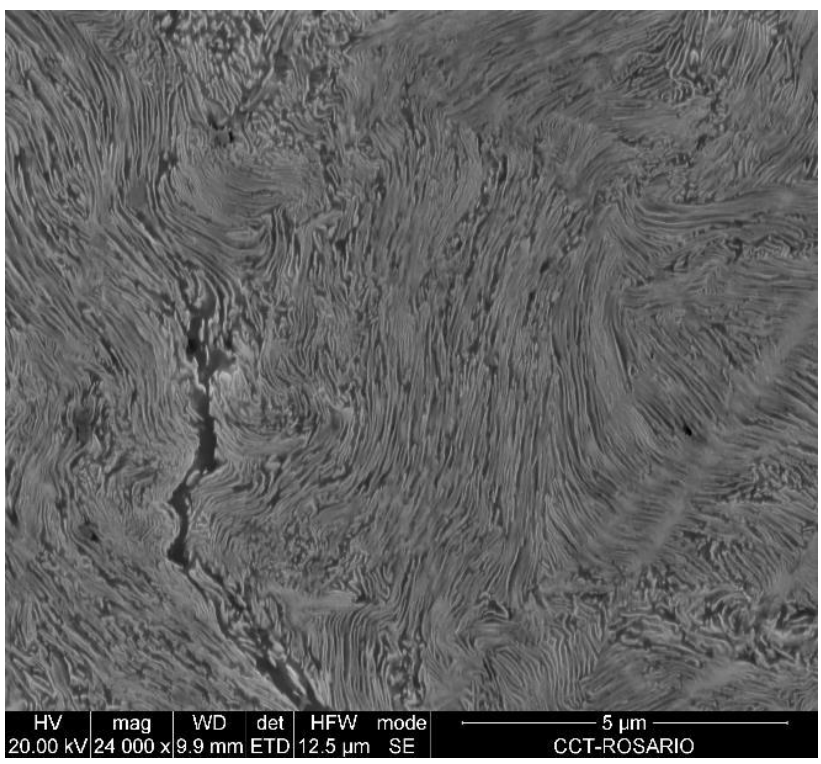

Fig. 1. Curling effect of the pearlite colonies observed in the centre of a cold drawn wire transversal sample.

The cementite lamellae with the initially random orientation become progressively aligned along the drawing axis with the increase of drawing strain.

A $<110>$ body-centered-cubic wire texture is developed in the ferrite. The combination of closely spaced ductile ferrite and high strength cementite lamellae makes possible exponential increases of strain hardening as a function of strain. The strength of the eutectoid steels is associated with the interlamellar spacing between the cementite, the lamellae refinement effect and the carbon concentration at grain boundaries, following Hall-Petch type equation (1) described in $[\mathbf{8}, \mathbf{1 1}]$ :

$$
\sigma_{y}=\sigma_{i}+k_{y} d^{-1 / 2}
$$

where $\sigma_{\mathrm{y}}$ is the lower yield stress, $\sigma_{\mathrm{i}}$ is the friction stress, $\mathrm{k}_{\mathrm{y}}$ is the strengthening coefficient and $\mathrm{d}$ is the grain size.

The theoretical basis for this equation relies on the stress intensification at the head of the dislocations and in the interaction between them with the grain boundaries. The grain boundary offers a resistance to the dislocations and promotes the pile up of them.

Cementite is a brittle compound, but in pearlitic structures, the fracture resistance is a function of lamellae thickness. In microstructures where the interlamellar spacing is $0.10 \mu \mathrm{m}$ or less, cementite shown to be plastic [10].

As is known, cementite is a stable phase at room temperature. However, the question arises as to the mechanism of cementite dissolution due to high plastic deformation. Ivanisenko et al. in [4], assumed that during SPD, dislocations cross the cementite layers or lamellas and drag carbon atoms with them, out of the cementite layer. In consequence, a refinement of the lamella is produced promoting cementite thermodynamic instability. This could be due to the high contribution of interface energy, especially when localized strain of a nonequilibrium structure are present. In $[\mathbf{1 1}, \mathbf{1 2}]$, the authors also describe cementite deformation mechanisms which result in a partially dissolution of the carbide compound. The carbon in solution in the ferrite contribute to dynamic strain aging at low temperature deformation.

Nematollahi et al. in [7], have studied the stabilization of interstitial $\mathrm{C}$ excess in the ferrite matrix and its influence on strength. Atom probe results reveal that carbon atoms segregate to ferrite lattice defects and grain boundaries, reaching up to 1 at.\% after wiredrawing. Min et al. in [13], suggest that a larger binding energy between carbon atoms and dislocations of the ferrite than between carbon and cementite makes possible the cementite destabilization and carbon drag out from the cementite lamellae.

In the industry the mechanical properties aptitude of the pearlitic wires products, are controlled by torsion tests up to rupture. The torsion test induce the material to heavy plastic deformation by shearing of the material, parallel to the flat surface of the cylindrical sample. The shear strain $\gamma$ developed by conventional torsion can be estimated applying the equation (2):

$$
\gamma=\frac{2 \pi N R}{h}
$$

where $\mathrm{R}$ is the distance from the sample centre, $\mathrm{N}$ is the number of the anvil rotations and $\mathrm{h}$ is the thickness of the sample. When wires under torsion test up to rupture present a flat fracture a normal mechanical behaviour is obtained, see Fig. 2(a). When a spiraling fracture is observed, the delamination problem is detected, Fig. 2(b). Delamination allows determine mechanical properties degradation of the product [1, 10-17].

Zelin in [17], talks about different microstructural changes occurring during wiredrawing that result in a record strength. Through differential scanning calorimetry (DSC) demonstrates the epsilon carbide $(\varepsilon)$ formation during drawing due to dynamic aging at temperatures between $150^{\circ} \mathrm{C}$ to $175^{\circ} \mathrm{C}$. The authors in $[1,10]$ in coincidence with Zelin predict the epsilon carbide formation through the cementite destabilization phenomenon applying thermodynamic simulation and corroborate the temperature of the precipitation by differential calorimetry (DSC).

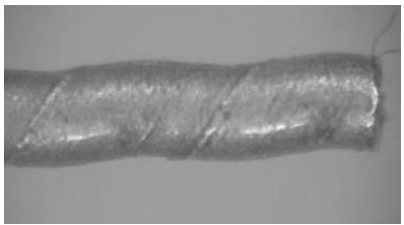

(a)

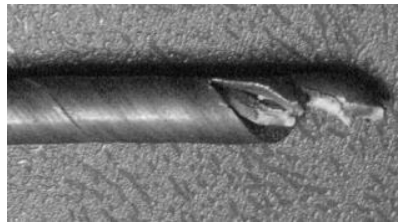

(b)
Fig. 2. Fracture surface post torsion test. (a) Normal flat surface (b) Delaminated surface. 


\section{High deformation effects on wire structure}

Major processes affecting microstructure in pearlitic steels during cold drawing, have been described by different authors $[1,4,7,10,13-17]$. They consider different aspects such as cementite lamellae thinning, evolution of lamellae interfaces, texture changes, metallographic texture, crystallographic texture, plastic flow localization, dynamic strain aging and thermodynamic aspect of the cementite dissolution.

\section{Lamellae thinning}

In 1976, Marder define the pearlite colony as areas where cementite and ferrite lamellae are arranged unidirectionally. At that time, the author also assumed that this microstructural unit in pearlitic steels dominates the mechanical properties. He considered that strength solely depend on the interlamellar spacing of cementite [15].

Kumar et al. shows the structure aspect of wire samples drawn to different strain levels (up to $\varepsilon \approx 0.63$ ) in which the starting material shows randomly oriented pearlitic colonies of different sizes. However, during the wire drawing the lamellae have a tendency to orient along the drawing axes. In addition, bending and kinking of cementite was observed during the samples deformation [14]. Similar effects were reported by other authors in $[1,10,17]$. Recently, Nakada et al. in [16], through electron backscatter diffraction (EBSD) method corroborate that crystals orientations of ferrite and cementite lamellaes in pearlite are not identical.

Kumar et al. in [14], reveal that the cementite lamellae oriented parallel to the wire axis get thinned further leading to fibrous structure. In [1] the author informs that in a $(0.84 \% \mathrm{C})$ pearlitic highly drawn wire (up to $3.25 \mathrm{~mm}$ of diameter), the ferrite and cementite lamellae reach thicknesses of 30 to $35 \mathrm{~nm}$. The interlamellar spacing in the wire with normal mechanical behaviour is $<100 \mathrm{~nm}$ in the periphery of the wire and less than $80 \mathrm{~nm}$ in the core of the wire. The greatest degree of interlamellar reduction was observed in the wire core $\approx 34 \%$ higher than in the periphery of the wire. In Fig. 3, the thickness of the cementite plates and the interlamellar spacing corresponding to one measurement field carried out by scanning electron microscopy (SEM) in the center of the wire is observed.

Zelin in [17], informs that cementite lamellaes with a thickness about $100 \mathrm{~nm}$ becomes highly plastic. The ferrite and cementite lamellaes thicknesses decreases to a few nanometers in a heavily drawn wire. For this reason, the author consider the heavily drawn pearlite wire as a nano-composite. The curling appearance of pearlite plates become more pronounced with increased drawing strain. In addition, a difference in deformation of pearlite colonies with different spatial orientation and strain localization is reported.

In $[1,10]$, the results obtained of the comparison between normal and delaminated pearlitic wires behaviour agree with Zelin affirmations. In addition, cementite lamellaes present fibers due to intensive cold deformation. The fiber diameter is around $28 \mathrm{~nm}$.

Based on the above descriptions it is possible to consider a change in the nature of the ferrite-cementite interface.

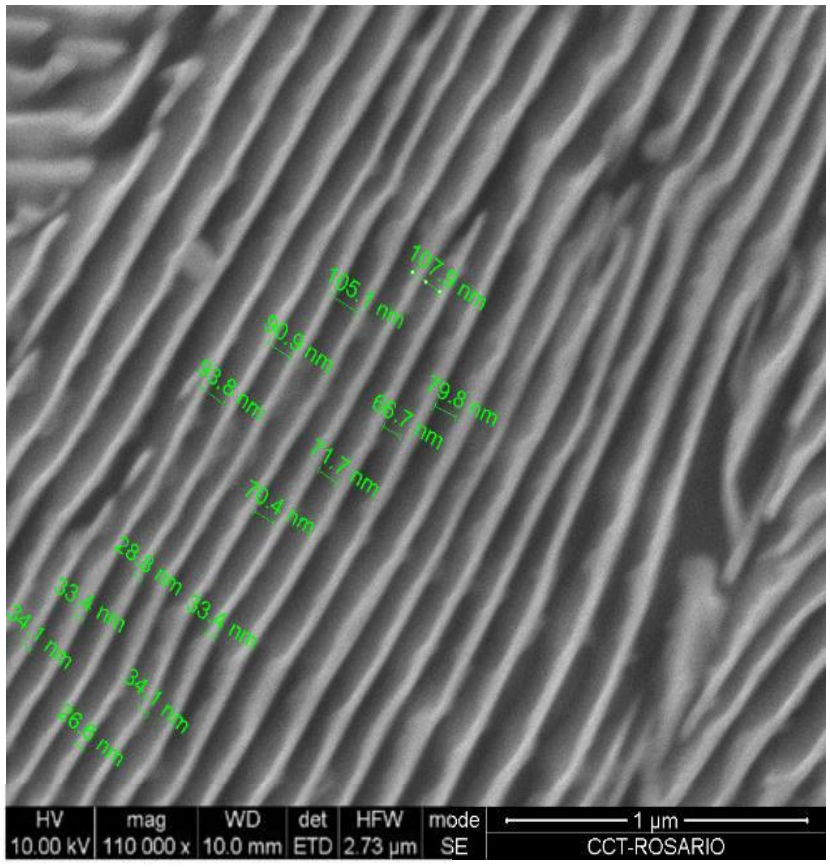

Fig. 3. Results of cementite lamellae thickness and interlamellar spacing measurements carried out in the center of the wire.

Nam et al. inform that by further straining, the shear bands tend to cause shear cracking of the cementite [18]. In Fig. 4 the phenomenon mentioned by Nam et al. is observed in the delaminated wire sample studied where the cementite plates shows shear cracking.

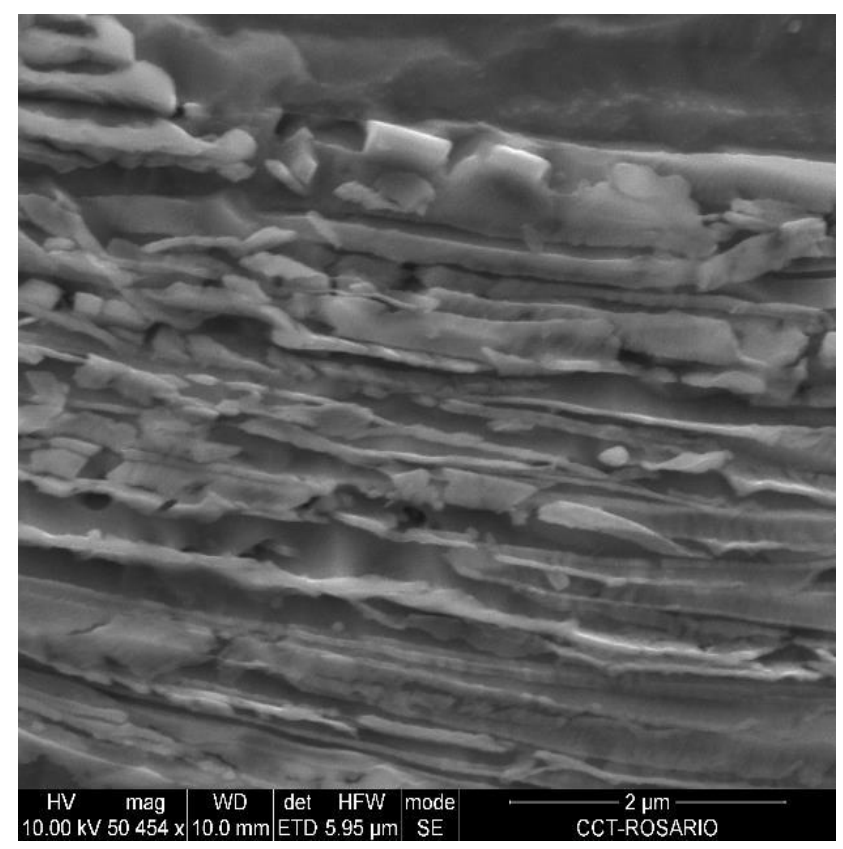

Fig. 4. Fragmentation and shear cracking observed in the cementite plates after cold drawing. 


\section{Evolution of lamellae interfaces}

While the volume of the wire is constant, its surface area increases with strain. For a pearlite colony, the lamellae surface (ferrite/cementite interface) also increase. The width and length are significantly larger than the thickness [17]. The huge increase in interfacial area bring an additional driving force for cementite dissolution during wire drawing [18]. Deformation causes changes of the nature of interlamellar interfaces that could be coherent or semi-coherent, affecting the interface energy. The slip systems $<111>\{110\}$ in ferrite and $\{100\}$ in cementite induce the accumulation of misfit dislocations at the interfaces leading to high elastic stress [17].

Ivanisenko et al. in [4], believe that the interface present a non-equilibrium structure with high energy, especially when the interface has high accommodation strains. There are kinetic factors that may contribute to generate high density of dislocations and grain boundaries that could provide rapid diffusion channels and adiabatic heating during plastic deformation. Borchers et al. have observed by high-resolution TEM that ferritic grains are separated by thin strips of quasi-amorphous material associated with cementite [19]. Van Acker et al. [20], have determined by neutron diffraction measurements the interlamellar stresses reach around $2000 \mathrm{MPa}$.

\section{Texture development}

Mechanism of reorientation of pearlite colonies can directly linked to dislocation slip. Operation of dislocation slip systems, localized shear and the curling of lamellaes, result in colony rotation. The rotation towards the wire axis, develop a [110] fiber texture [17]. Fig. 5 shows the pole figures: (110), (100) and (211) obtained by X ray diffraction on two wires cold drawn up to $3.5 \mathrm{~mm}$ of diameter with normal Fig. 5(a) and delaminated behaviour Fig.5 (b).

The texture evolution in the wires after cold drawing from $9 \mathrm{~mm}$ to $3.25 \mathrm{~mm}$ of diameter corroborates the presence of a fiber texture $\langle 110\rangle$. In both samples, the pole figures present a symmetric circular distribution with a maximum intensity $(\approx 9)$ in the center in coincidence with the fiber $\langle 110\rangle$. The random texture aspect observed is consistent with the curling of the pearlite colonies determined by scanning electron microscopy (SEM). No appreciable differences were found in the texture between the wire with normal and delaminated behaviour $[\mathbf{1}, \mathbf{1 0}]$. The results are consistent with the pearlitic wire texture descriptions presented in $[\mathbf{1 4}, \mathbf{1 7}]$.

The [110] fiber texture results in an alignment of (001) planes, which are the cleavage planes in ferrite, along wire axis [17]. The authors in [7, 14], assume that the activation of $\{110\}<111>$ in ferrite and $\{110\}$ slip in cementite causes the accumulation of misfit dislocation at the interface.

In coincidence with Suzuki et al. the residual strains in (100) and (211) lattice planes are different respect to the observed in (110). On this base, other origins of

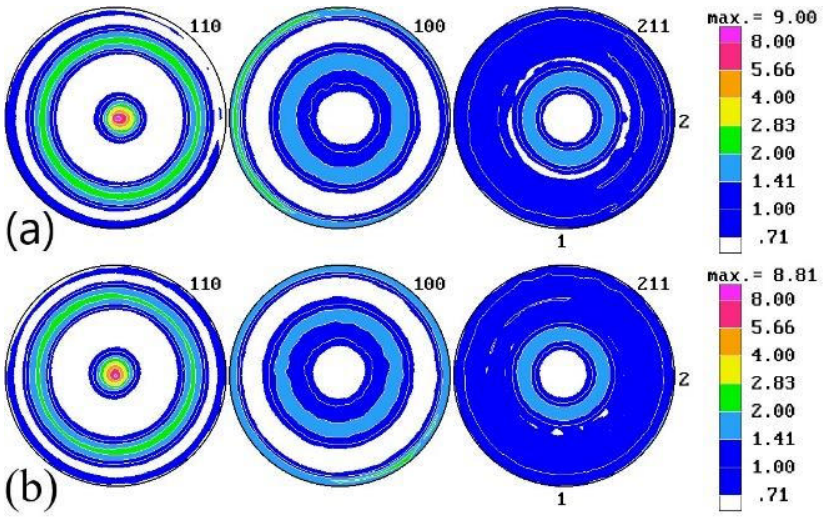

Fig. 5. $X$ ray diffraction results obtained on two cold drawn wire samples (up to $3.25 \mathrm{~mm}$ ): a) Normal b) Delaminated.

residual stress are proposed caused by differences in flow stress between ferrite and cementite lamellaes with different inclinations. Therefore, development of residual stress may be responsible to produce the ultra-high strength in pearlitic steel wires [21]. The relationship between strength anisotropy and residual stress contribute to understand the ultra-high strength achieved of cold drawn pearlitic steel wires [14-21].

\section{Plastic flow and crystallographic texture}

It is evident that plastic deformation during wire drawing is non-uniform and a small fraction of the mechanical energy is stored in the metal, mostly associated with dislocations. Two systems of localized shear bands are formed oriented from 30 to 45 degrees with respect to the wire axis. Local shear increases with drawing strain. These shear surfaces can be activated under tensile load leading in strain localization which is an important factor controlling overall elongation. Localized shear bands divide material into cells.

Nakada et al. by electron backscatter diffraction (EBSD) observations confirm that crystal orientations of ferrite and cementite rotate in a blocks. The elastic misfit strain strengthens the ferrite matrix and contributes to the high strength of pearlitic steel [16]. The misfit strain is not completely accommodated by interfacial structures and remains as elastic strain, leading in the crystal rotation.

Ivanisenko et al. in [4], through TEM observations verify the presence of high dislocations density in the ferrite, indicating the formation of low angle boundaries. The results shows that the ferrite structure is nonhomogenous with areas with cellular structure and nanostructured regions with elongated grains of $20-50 \mathrm{~nm}$ of diameter and 100-150 nm of length. Dense dislocation walls with high angle misorientations between them separate grains.

The authors in agree with Flecht and Valiev, describe that during SPD the nanostructure formation involve three different stages. The first stage corresponds to formation of cell structure in the ferrite and a considerable 
dissolution of cementite occur $(\approx 40 \%)$. During the second stage, the number of dislocations in the cell boundaries increase and results in high angle grain boundaries formation.

The cellular structure is transformed progressively to nanocrystalline-elongated grains of $100 \mathrm{~nm}$ length and $15 \mathrm{~nm}$ diameter.

In the third stage, the homogenization of the nanocrystalline structure occurs resulting in a nanocrystalline structure with a mean grain size of $10 \mathrm{~nm}$. In Fig. 6 the IQ+IPF map obtained by EBSD in a wire sample cold drawn up to $3.25 \mathrm{~mm}$ of diameter, corroborates the presence of an intermediate nanostructure evolution between the mentioned first and the second stage.

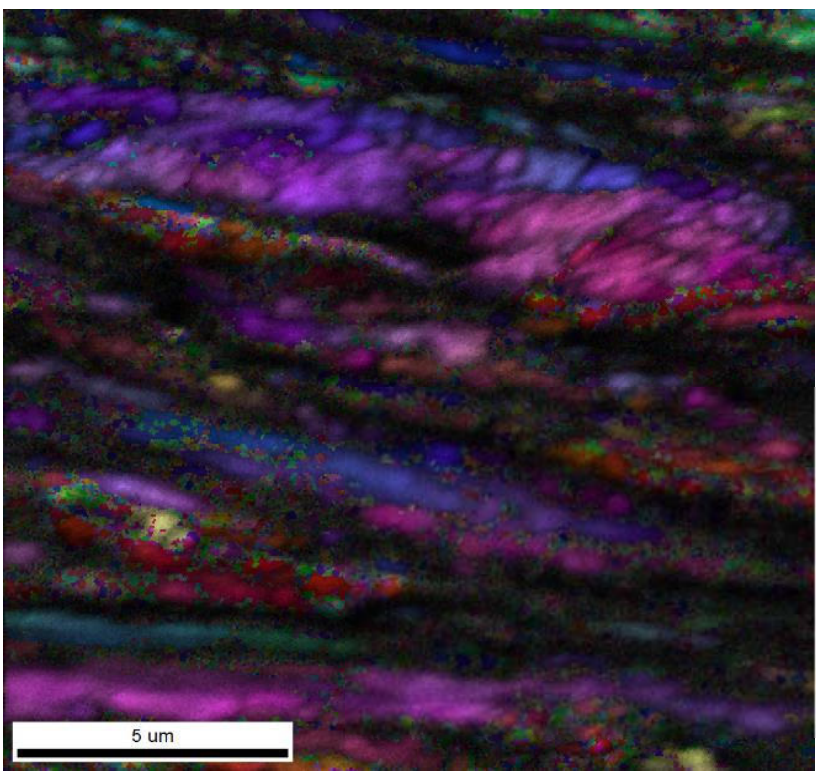

[001]

\section{[001]}
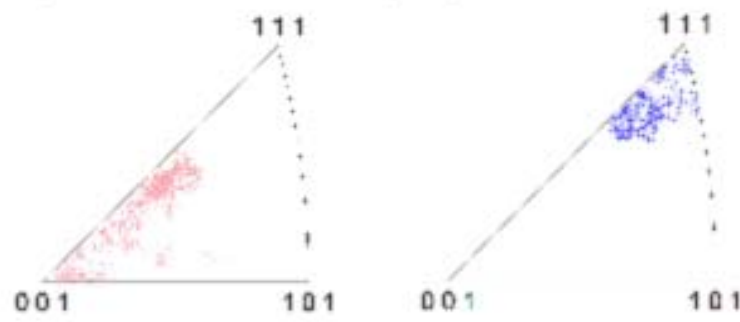

Fig. 6. IQ + IPF map obtained by EBSD on a wire sample cold drawn up to $3.25 \mathrm{~mm}$ of diameter.

In the ferrite matrix the presence of cells and nanocrystalline-elongated grains are determined. The distribution of misorientations allows to identify the presence of low and high angle boundaries.

It is possible to explain the dissolution of cementite based on thermodynamic equilibrium considerations of the metastable phases. Heavy plastic deformation leads to thinning and fragmentation of precipitates. For small precipitates, the relaxation of interface energy and interface stresses provides a high driving force to promote cementite dissolution.
Borchers et al. have showed that ferrite grains remain elongated in contact with partially amorphous cementite accompanied by carbon depletion from cementite. They considered that when cementite is deformed during wire drawing, the cut caused through dislocations, promote the antiphase boundaries formation in cementite lamellae. The effect contribute to carbon drag, causing a high density of vacancies in the cementite. This structure evolution result in the so attractive mechanical properties combination for engineering applications [19]. Ivanisenko et al. in [4], determined that during the first stage of the nanostructure evolution, around $40 \%$ of cementite is dissolved.

\section{Dynamic strain aging}

Nematollahi et al. [5] describe that cementite present an orthorhombic unit cell that contains $12 \mathrm{Fe}$ atoms and $4 \mathrm{C}$ atoms. The Fe atoms are located in different lattice sites ( $\mathrm{Fe} 2$ and $\mathrm{Fe} 1)$. The nearest-neighbour atoms around $\mathrm{C}$ are $2 \mathrm{Fe} 1$ and $4 \mathrm{Fe} 2$, form a trigonal prism in the centre of which the $\mathrm{C}$ atom is located. Two different orientations of these prisms are possible in the cementite structure that respond differently to the applied load. Cementite is very stable at room temperature however heavy plastic deformation could lead to their thermodynamic instability $[4,10]$.

Dissolution of cementite observed during wire drawing has been attributed to dragging of carbon by the ferrite dislocations crossing cementite lamellae, resulting in over-saturation of ferrite with carbon [17]. The $\mathrm{C}$ addition in the ferrite expands the bcc lattice in the direction of the two nearest-neighbour $\mathrm{Fe}$ atoms around the interstitial $\mathrm{C}$ [7]. Borchers et al. have observed that the carbon content in the cementite lamellae decrease after cold drawing and it is lower than in equilibrium cementite. However, substantially higher than in ferritic matrix.

The carbon atoms ejected during cementite dissolution segregate at dislocations in the ferrite and locked them by the Cottrell atmosphere effect [19]. Cementite plates are progressive dissolved and becomes of a few atomic layers.

Zelin in [17] has considered that the adiabatic heat increase caused by plastic deformation, is justified by the over-saturation of the ferrite with carbon atoms, which promotes the wire heating at temperatures between 150 to $250^{\circ} \mathrm{C}$. By differential scanning calorimetry (DSC) determined that at this temperature range, the epsilon carbide $(\varepsilon)$ precipitation is produced. This carbide contributes to the dynamic strain aging during cold drawing process. The precipitation in excess could cause delamination It is possible to think that the increase of drawing speed could promote the delamination susceptibility of the wire through an excessive epsilon carbide $(\varepsilon)$ formation.

The comparative study of wires with normal and delaminated behaviour carried out by Brandaleze in [10], confirms that dynamic aging occur at low temperatures in pearlitic wires $(>0.8 \% \mathrm{C})$. The results also shows that the 
delaminated wire produces a greater heat liberation during the DSC tests performed up to $600^{\circ} \mathrm{C}$ at a heating rate of $5^{\circ} \mathrm{C} / \mathrm{s}$. The DSC curves have showed that the epsilon carbide formation $(\varepsilon)$ for the samples occur at temperatures between $151^{\circ} \mathrm{C}$ to $185^{\circ} \mathrm{C}$. Bala et al. [22], determines the epsilon carbide $(\varepsilon)$ precipitation in low alloy medium carbon steels through a positive dilatation effect at the same temperature $\left(\approx 150^{\circ} \mathrm{C}\right)$ by dilatometry.

Nematollahi et al. in [7], also report the initial stage of strain ageing at $160^{\circ} \mathrm{C}$ determined through DSC tests. The $\mathrm{C}$ accumulation in defects, grain boundaries and dislocation cores is attributed to the severe plastic deformation, which cause the carbon transfer from cementite-ferrite interface to the ferritic lamellaes.

\section{Delamination problems}

Delamination is a fracture phenomenon in which cracks propagate along the longitudinal direction of a wire during torsion test $[\mathbf{2 3}, \mathbf{2 4}]$. Bae et al. have mentioned that is one of the qualitative indication of a decrease in ductility [25].

Different mechanisms have been proposed to explain the onset of delamination: dynamic strain aging, residual stress and drawing conditions. However, the origin of delamination has not been completely clarified yet.

Bae et al. provide the evidence that voids at globular cementite particles generated by plastic deformation could be one of the possible delamination cause [25]. The study in [10], corroborates that the structure of the delaminated wire present cementite globulization and fragmentation effect. The cementite globules present $48 \mathrm{~nm}$ of diameter. In addition, the epsilon carbide $(\varepsilon)$ precipitation together with a content $(70 \mathrm{ppm})$ of $\mathrm{N}_{\text {free }}$ in the material, justified the behaviour of the delaminated sample. Both factors allows to think in a more enhanced dynamic strain aging effect that promotes the ductility decrease of the delaminated wire sample. In agree with Su et al. in [26], it is relevant to prevent deterioration of ductility due to strain aging caused by carbon and nitrogen. Dislocation immobilization caused by interstitial nitrogen and carbon atmospheres can be minimized by proper thermal treatment during manufacturing process.

Tanaka et al., by Electron Backscatter Diffraction (EBSD) have observed that delaminated fracture zones in pearlitic wires present effects caused by severe plastic deformation (SPD). They concluded that delamination not present complete brittle cracks [26].

\section{Thermodynamic aspects}

In order to understand the structural evolution of deformed pearlitic steel, Sabat et al., have studied pearlitic wires subjected to hot deformation between $400^{\circ} \mathrm{C}$ to $600^{\circ} \mathrm{C}$, considering different strain rates. They justify the ductility behaviour achieved in the steel product through a cementite dissolution phenomenon which also is possible at lower temperatures combined with high deformation [9].
Ivanisenko et al. mention two approaches to explain the cementite dissolution [4]. One approach is based on the thermodynamic equilibrium of the metastable phases and other on the ballistic models where movement of matter is caused by external factors. The results confirm that most of the dissolved carbon is sited in dislocation cores or grain boundaries. SPD leads to thinning and fragmentation of precipitates. For small precipitates, the relaxation of interface energy and interface stresses provides a high driving force for the precipitates dissolution. Very small precipitates may become coherent with the matrix and the interface stress factor may vanish.

In cold drawn the plastic deformation occurs at room temperature and the diffusion coefficient is negligible. The dominant transport mechanism is connected with the plastic deformation. However, Ivanisenko assume a combination of thermal diffusion and mechanical diffusion on the base of experimental measurements.

It is a general observation that the flow stress increases with a reduction in the structural scale. This strength increase relates to different strengthening parameters for example the dislocation density and the fraction of medium and high angle boundaries $[\mathbf{2 7}, \mathbf{2 8}]$.

However, the high strain energy accumulated in the carbides, strongly contribute to the cementite instability. The flow of carbon is considered as a mechanically driven mass transport process described by the mechanical diffusion parameter. From a thermodynamic point of view, the carbon concentration in the ferritic layers of the severely plastically deformed pearlitic wires is controlled by various effects: the strain-induced stabilization of interstitial $\mathrm{C}$ in ferrite, the dissolution of cementite and the interfacial tension between the two phases (which depends on the distribution of carbon across the interface) [7].

In addition, the epsilon carbide $(\varepsilon)$ precipitation is possible in the interface between ferrite and cementite or in the supersaturated ferrite during cold drawing $[\mathbf{1 0}, \mathbf{1 7}$, 22].

The thermodynamic simulation of iron carbides stability carried out in [10] has showed that the epsilon carbide $(\varepsilon)$ is the most probable to precipitate when cementite becomes unstable.

\section{Conclusion and future perspectives}

In the design and characterization of high performance steels as the ultra-high strength perlite steels, the nanoscale has opened new frontiers to continue understanding the impact of the mechanisms of severe plastic deformation, which explain the structure evolution and the mechanical behaviour.

It is relevant to continue the research on the nature of interfaces, the nanostructure evolution, the mechanisms at atomic scale of the cementite dissolution and the strainaging phenomenon, in order to explain the so attractive mechanical properties combination of the pearlitic wires with extreme carbon content. 
The results corroborate that the cementite destabilization constitute an important aspect in the strength development. The epsilon carbide $(\varepsilon)$ precipitation during cold drawing and their relation with the nanostructure could clarify the impact on the mechanical properties, including the effects in delamination problems.

The information is necessary for the industry in order to improve the manufacturing processes and for the design of new ultra-high strength alloys.

\section{Acknowledgements}

The authors gratefully acknowledges the for financial support by the Universidad Tecnológica Nacional. The authors also thank Dr. $R$ Bolmaro at IFIR CONICET for helpful discussions on the cold drawn deformation mechanisms.

\section{References}

1. Brandaleze, E.; Procedia Mat. Scien.; 2015, 8, 1023. DOI: $10.1016 / \mathrm{j} . \mathrm{mspro} .2015 .04 .164$

2. Di Schino, A.; Di Nunzio, P.E.; Cabrera, J.M.; Adv. Mat. Lett., 2017, 8, 5, 641 .

DOI: $10.5185 /$ amlett.2017.1487

3. Llewwllyn, D.T.; Hudd, R.C. (3 ${ }^{\text {rd }}$ Eds.); Steels Metallurgy and Applications; Butterworth Heinemann: UK, 1998.

ISBN: $978-0-7506-3757-2$

4. Ivanisenko, Y.; Lojkowski, W.; Valiev, R.Z.; Fecht, H.J.; Act. Mat., 2003, 51, 5555 .

DOI: $10.1016 /$ S1359-6454(03)00419-1

5. Rodríguez Ripoll, M.; Očenášek, J.; Eng. Fract. Mech.; 2009, 76, 1485.

DOI: $10.1016 /$ j.engfracmech.2009.02.012

6. Bolmaro, R.E.; Fourty, A.; Signorelli, J.W.; Brokmmeier, H. G.; Modelling Simul. Mater. Sci. Eng.; 2005, 13, 1.

DOI: $10.1088 / 0965-0393 / 13 / 2$

7. Nematollahi, G.A.; Von Pezold, J.; Neugebauer, J.; Raabe, D.; Act. Mat., 2013, 61, 1773 .

DOI: $10.1016 /$ j.actamat.2012.12.001

8. Li, Y.J.; Choi, P.; Goto, S.; Borchers, C.; Raabe, D.; Kirchheim, R.; Act. Mat., 2012, 60, 4005.

DOI: $10.1016 /$ j.actamat.2012.03.006

9. Sabat, R.K.; Hatwal, S.; Dixit, B.; Suwas, S.; Mat. Scien. Forum, 2013, 753, 459 .

DOI: $10.4028 /$ www.scientific.net/MSF.753.459

10. Romanyuk, M.; Brandaleze, E.; Rev. Ad. In Scien. and Eng.; 2016, 7, 3, 55 .

ISBN: $0718-8706$

11. Krauss, G.; ( ${ }^{\text {nd }}$ Eds.); Steels processing, structure and performance; ASM International, USA, 2015. ISBN: 0871708175 (ISBN13: 9780871708175)

12. Gladman, T. ( $1^{\text {st }}$ Eds.); The physical metallurgy of microalloyed steels; Maney: UK, 2002.

ISBN: 0901716812

13. Min, N.; Li, W.; Li, H.; Jin, X.; J. Mater. Sci. Technol., 2010, 26, 9 , 776.

DOI: $10.1016 / \mathrm{S} 1005-0302(10) 60123-5$

14. Kumar, P.; Gurao, N.P.; Haldar, A.; and Suwas, S.; ISIJ International; 2011, 51, 4, 679.

DOI: $10.2355 /$ isijinternational.ISIJINT/51/4/51/4/679

15. Marder, A.R.; Bramfin, B.L.; Metall. Trans. A, 1976, 7A, 365. DOI: $10.1007 / \mathrm{BF} 02642832$

16. Nakada, N.; Koga, N.; Tanaka, Y.; Tsuchiyama, T.; Takaki, S.; Ueda, M.; ISIJ International; 2015, 55, 9, 2036.

DOI: $10.2355 /$ isijinternational.ISIJINT-2015-102

17. Zelin, M.; Act. Mat.; 2002, 50, 4431.

DOI: $10.1016 / \mathrm{S} 1359-6454(02) 00281-1$
18. Nam, W.J.; Bae, C.M.; Oh, S.J.; Kwon, S.J.; Scripta mater; 2000, $42,457$.

DOI: $10.1016 / \mathrm{S} 1359-6462(99) 00372-3$

19. Borchers, C.; Al-Kassab, T.; Goto, s; Kircheim, R.; Mat. Sci. and Eng. A; 2009; 502, 131.

DOI: $10.1016 /$ j.msea.2008.10.018

20. Van Acker, K.; Root, J.; Van Houtte, P.; Aernoudt, E.; Acta Matter.; 1996, 44, 4039 .

DOI: $10.1016 / \mathrm{S} 1359-6454(02) 00281-1$

21. Suzuki, T.; Tomota, Y.; Isaka, M.; Moriai, A. ; Minakawa, N.; Morii, Y.; ISIJ International; 2004, 44, 8, 1426.

DOI: $10.2355 /$ isijinternational1989/44/8/44.8.1426

22. Bala, P.; Pacyna, J.; Krawczyk, J.; Arch. Of Mat. Sci. and Eng.; 2007, 28, 2, 98

DOI: $\underline{10.1 .1 .515 .5146}$

23. Shimidzu K.; Kawabe, N.; ISIJ International.; 2007, 28, 2, 98. DOI: $10.2355 /$ isijinternational2007/28/2/

24. Bae, C.H.; Nam, W.J.; Lee, C.S.; Scripta. Mat.; 1996, 35, 641. DOI: $10.1016 / 1359-6462(96) 00183-2$

25. Su, Y.Y.; Shemenski, R.M.; Mat. and Design; 2010, 31, 1423. DOI: $10.1016 /$ j.matdes.2009.08.038

26. Tanaka, M.; Saito, H.; Yasumary, M.; Higashida, K.; Scripta. Mat.; 2016, 112, 32.

DOI: $10.1016 /$ j.scriptamat.2015.09.004

27. Hansen, N.; Key Eng. Mat.; 2007, 353-358, 9. DOI: $10.4028 /$ www.scientific.net/DEM.353-358.9

28. Valiev, R.Z.; Diffusion foundations; 2015, 5, 43. DOI: $\underline{10.4028 / \text { www.scientific.net/DF. } 5.43}$ 